\title{
A Research on National Sustainability Evaluation Model
}

\author{
Ge Fan \\ Department of business \\ Sichuan Agricultural University \\ Chengdu, China \\ fange1122@gmail.com
}

\author{
Shan Sun \\ Department of Economics and Trade \\ Hunan University of Commerce \\ Changsha, China \\ sunshan920813@gmail.com
}

\author{
Wei Peng* \\ Department of business \\ Sichuan Agricultural University \\ Chengdu, China \\ pw7@163.com \\ Peiwen Li \\ Department of Mechanical Engineering \\ Donghua University \\ Shanghai, China \\ lipeiwen@me.com
}

\begin{abstract}
By applying an objective method to evaluate its sustainability, a certain country could make proper plans and policies for further development. However, subjective and complicated problems have been found in the current methods and index systems. Therefore, researchers set up a composite model that it can evaluate the sustainability for a certain country in a more objective way, in comparison with other methods. Researchers propose a method for evaluating sustainability for a certain country, which solves problems concerning strong subjectivity and complicity in current models. Researchers choose 17 representative core indicators based on the index system of UNCSD and divide them into two catalogues -- Nature Indicators and Operate Indicators. First, Means Clustering Algorithm of k-means (an unsupervised learning method) divides the data into three categories. Then, researchers obtain those indicators, using regression analysis, and build an objective evaluation model. When researchers make policies for a country to allocate resources reasonably, researchers maximize the improvement of the ability of sustainable development based on "along the gradient direction ascend the fastest". In this paper, researchers conduct simulations experiment, using data of 96 countries in the World Bank. After analyzing the deviations and sensitivity of the model, the theoretical results are verified experimentally.
\end{abstract}

Keywords-mechine learning; $k$-means; logistic regression; neural network; sustainability

\section{INTRODUCTION}

The growing number of global population has brought the deterioration of vulnerable environment and the depletion of available resources. As a result, it is not mere the growth of economy but the efficiency in utilization of natural resources that becomes the sigh of the strength of a country.

From 1987, when World Commission on Environment and Development (WCED) officially put forward the idea of sustainable development [1], this has become the ideal pattern and goal for human development. Evaluations about it plays an important role in researches of sustainable development, for those evaluations could provide both long-term and short-term operating information under different dimensions and give support to decision makers[1], The Evaluation Index System of sustainable development also has been proved in practice to be an effective appraisal tool, as this system shows the sustainability of a country in such fields as environment, economy, social and technology[2] as well as simplifies and quantifies complicated information[3].

Now, people divide the framework of the Evaluation Index System into two parts, economics base and natural resources base. The framework of economics is built on the basis of mainstream economics, which believes that currency could represent resource value and comprehensive value. Among them, "Green" GDP and the Index of national wealth are the methods common used [4, 5].

Among researches based on resources, a famous index is the five-year-lasting CSD Work Programmed on Index of Sustainable Development authorized by the United Nations Commission on Sustainable Development (UNCSD) in 1995. Model "Drive-State-Respond"(DSR) builds the system that is based on Agenda 21, and this system is divided into four dimensions-economic, social, environment and institution. The index system suggested in 1996 has 134 indicators, in which there are 23 economic indicators, 41 social indicators, 55 environment indicators and 15 institution indicators [6]. Another model commonly used is model Ecological Footprint [7], which compares all the consumable resources to meet the demand of people from a specific area to all the biologically productive area needed to absorb the waste produced by these people, and sees if this area could develop sustainably.

\section{MODEL OF CONSTRUCTION AND COMBINATION}

Researchers believe that to assess the degree of sustainable development of a country rationally, the initial approach includes the following two steps:

1). Find out the rational indicators.

2). Give every indictor a rational influence coefficient. 
Definition 1, indicator $\mathrm{x}$ and regression function $\mathrm{f}(\mathrm{x})$ that shows the degree of sustainable development composes the influence coefficient $\mu(x)=\frac{\partial f(x)}{\partial x}$.

For step 1, previous studies have proposed many index systems. Nevertheless, these systems have either an enormous structure or a narrow research scope, failing to evaluate the degree of sustainable development of a country or a policy correctly. Therefore, researchers decide to seek the right index system. Considering those many indicators in those systems are hard to control and that indicators that could directly reflect the degree of sustainable development of a country cannot measure the degree of a policy, researchers separate the indicators into two groups.

For step 2, the commonly used methods such as Analytical Hierarchy Process (AHP) and Expert Decision (Expert System Analyses) that determining the weights of indicators. Though this kind of methods has been widely used, they are subjective somehow, since people have difference mindset in determining weight. As the rise of Machine Learning, researchers hope to find an objective method to determine the weights of indicators by big data. Researchers first divide countries into several clusters with different degrees of sustainable development and cluster the data using an unsupervised method K-MEAN. Then researchers compare and analyze the results of this method with those of traditional methods, and determine the degree (highly sustainable development, sustainable development and unsustainable development) of each classification. Then researchers use methods such as logistic regression and neural network to analyze those indicators. By doing so, researchers reduce the influence of artificial subjective factors and make sure these weights are more objective.

\section{A. Selection of indicators}

Documents mentioned above provide multiple indicators. However, those indicators all have drawbacks in some degree. For instance, there are too many indicators and the data collection is too difficult to conduct, thus the index system of UNCSD is over huge. On the other hand, the range of ecologic footprint indicators and economic indicators is fairly narrow. Without considering factors such as national policy and health condition of residents, the results of previous methods might be biased.

In order to solve problems mentioned above, researchers decide to simplify index structure. International Institute of Sustainable Development ( IISD ) proposed ten Bellagio principles dimensions in the book Assessing Sustainable Development: Principles in Practice [8]:

- Guiding Vision and Goals

- Holistic Perspective

- Essential Elements

- Adequate Scope

- $\quad$ Practical Focus

- Openness

- Effective Communication

- Broad Participation

- Ongoing Assessment

- Institutional Capacity.
There is a selection of principles covering index systems of sustainable development. According to this principle, researchers select 17 common core and representative indicators from index system of UNCSD model as the model's metrics [6] and divide these indicators into two classifications: one could directly reflect the degree of sustainable development of countries; another could reflect the degree of sustainable development through factors such as politics. Details about indicators are in Table 1.

TABLE I. CATEGORY OF INDICATORS

\begin{tabular}{|c|c|}
\hline Indicator Tab & Indicator Detail \\
\hline \multicolumn{2}{|r|}{ Nature Indicators } \\
\hline$I_{1}$ & Arable land (percent of land area) \\
\hline$I_{2}$ & Forest area (percent of land area) \\
\hline$I_{3}$ & Combustible renewables and waste (percent of total energy) \\
\hline$I_{4}$ & Energy use (kg of oil equivalent per capita) \\
\hline$I_{5}$ & $\mathrm{CO} 2$ emissions (metric tons per capita) \\
\hline$I_{6}$ & Annual freshwater withdrawals, domestic (percent) \\
\hline \multicolumn{2}{|r|}{ Operation Indicators } \\
\hline$I_{7}$ & Life expectancy at birth, total (years) \\
\hline$I_{8}$ & Death rate, crude (per 1,000 people) \\
\hline$I_{9}$ & Internet users (per 100 people) \\
\hline$I_{10}$ & Improved sanitation facilities (percent of population with access) \\
\hline$I_{11}$ & GDP per person employed \\
\hline$I_{12}$ & Labor force participation rate, total (percent of ages $15+$ ) \\
\hline$I_{13}$ & Population growth (annual percent) \\
\hline$I_{14}$ & Mortality rate, under-5 (per 1,000 live births) \\
\hline$I_{15}$ & Cash surplus/ deficit (percent of GDP) \\
\hline$I_{16}$ & Net ODA received (percent of GNI) \\
\hline$I_{17}$ & Gross savings (percent of GDP) \\
\hline
\end{tabular}

Table 1 shows the details and classifications of indicators that include many factors such as demographic, natural resources, economic, social and political conditions and that are complied with Bellagio Principle.

\section{B. Preprocess the data}

Researchers collect all the countries' data covering the 17 indicators through World Bank Database [9]. After primary process, researchers have a dataset from 2002 to 2011, including 96 countries and 17 indicators. Researchers select data of 2002 as the modeling data.

First, researchers standardize the data. The equation of data normalization is as follows:

$$
X_{i k}^{\prime}=\frac{X_{i k}-\operatorname{Mean}\left(X_{i}\right)}{\operatorname{std}\left(X_{i}\right)}
$$

Among them, $X^{\prime}$ ik is the data of Xik after standardization, $\mathrm{Xi}$ is vector in the $\mathrm{i}$ row of matrix $\mathrm{X}$. 


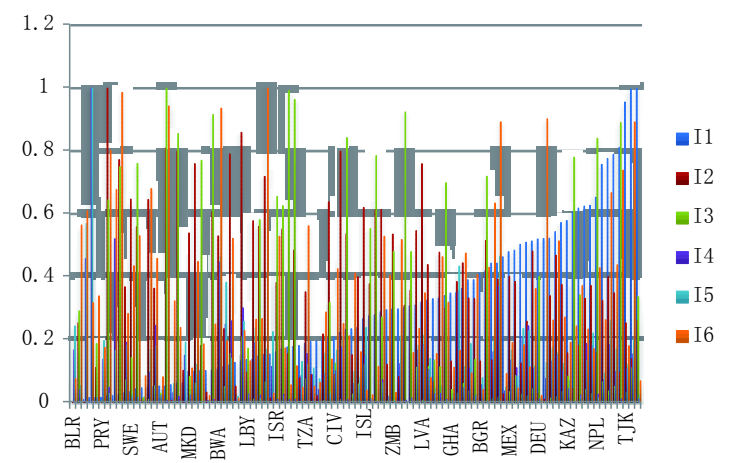

Figure 1. The figure of all country

After the process, indicators of those countries are shown in the Fig. 1.

\section{K-MEANS}

(1). Researchers assume that d properties describe one data observation, then $\mathrm{d}$ dimensions space consists of multiple data observation that have $d$ properties. Within the space, data observation called d-dimensional data point and the data point denote $\mathrm{X}=(\mathrm{X} 1, \ldots \ldots, \mathrm{Xd})$, and $\mathrm{i}$ represents the ith property values and $d$ denotes the dimensionality of space.

(2). Set $\mathrm{S}=(\mathrm{s} 1, \ldots \ldots, \mathrm{sn})$ consists of $\mathrm{n} d$-dimensional data point and $s=(\operatorname{sil}, \ldots \ldots$, sid $)$ denotes the jth property of the ith data point.

(3). According to the similarity among data points, the process of classifying $\mathrm{d}$-dimensional data set $\mathrm{V}$ into $\{\mathrm{C} 1, \mathrm{C} 2, \ldots \ldots, \mathrm{Ck}\}$ called cluster analysis, and $\mathrm{k} \leqslant \mathrm{n}$, $\mathrm{Ci} \neq \varnothing, \mathrm{Ci} \in \mathrm{V}, \mathrm{i}=1,2, \cdots \cdots \mathrm{k}$, and Ci's union set is $\mathrm{V}$ that is the cluster.

(4). Evaluating the similarity of data points according to their distances from each other. The shorter distance is, the more similar they are. On the contrary, the longer distance is, the less similar they are. To achieve better classification, highly similarity of observation within the same cluster and highly irrelevant between different clusters, researchers adopt the Euclidean metric in this model:

$$
d_{i j}=\left(\sum_{k=1}^{p}\left|x_{i k}-x_{j k}\right|^{2}\right)^{1 / 2}
$$

In ideal conditions, points and distance of data should satisfy the condition as follow:

Basically, the lower value the data is, the higher the similarity is; conversely, the greater value the data is, the less the similarity is.

Firstly researchers set up 3 centroids. Then researchers change the classification by reiteration and get a better classification than the previous, until the classification stabilizes. Therefore, researchers can get a cluster correspond to sustainability of each country, and then researchers can obtain every sustainability of country by analyzing the cluster.

In the Fig. 3, the three groups of countries are marked distinctively by red asterisk, blue plus and yellow circle.

Researchers classify the clusters into 3 groups. The first group consists of 46 countries, the second group consists of 25 countries, and the third group consists of 27 countries. The result of three groups of country's evaluation cluster is shown as picture. Considering the data visualization is feasible, researchers use PCA algorithm to transform the 6-dimensional information into 3dimensional information. The 3 dimensions is a dimension with the maximum amount of information, and it contributes $80.24 \%$ of the total amount of information. Researchers name the three dimensions I1', I2', I3' respectively in the order of information contribution from high to low.

In the picture, the three groups of countries is marked distinctively by red asterisk, blue plus and yellow circle. In order to verify the classification's accuracy and find out the highly sustainable countries, researchers contrasted multi-periods ecological footprint report.

Researchers contrast the reports of ecology footprints from several period of time [8-14]. The table below shows the comparison of results of cluster and the ones from ecology footprints report. Researchers can see from table 2, the results of ecology footprint reports and of the classification are basically the same. For example, FINLAND, SWEDEN, high-ranking countries in ecology footprints reports about the ability of sustainable developing, belongs to group1 in the classification. Moreover, middle-ranking country GABON belongs to the group2 and countries ranked on the bottom such as LEBANON, TUNISIA are in group3. So researchers can conclude that:

- $\quad$ from group 1 are highly sustainable developing;

- from group 2 are sustainable developing;

- $\quad$ from group 3 are least sustainable developing

TABLE II.

THE GROUP OF COUNTRY

\begin{tabular}{ccc}
\hline Country & Rank of LPR & Classification \\
\hline FINLAND & 1 & 1 \\
SWEDEN & 2 & 1 \\
NORWAY & 4 & 1 \\
$\vdots$ & $\vdots$ & $\vdots$ \\
GABON & 50 & 2 \\
$\vdots$ & $\vdots$ & $\vdots$ \\
LEBANON & 60 & 3 \\
TUNISIA & 64 & 3 \\
\hline
\end{tabular}

\section{LOGISTIC REGRESSION}

Let the test data for $\mathrm{X}(\mathrm{x} 0, \mathrm{x} 1 \ldots \mathrm{xn})$ he parameters that after processing For $\Theta(\Theta 0, \Theta 1 \ldots \Theta n)$

$$
Z=\Theta_{0} x_{0}+\Theta_{1} x_{1}+\ldots+\Theta_{n} x_{n}
$$

In vector

$$
Z=\Theta_{0}^{T} X
$$

$\mathrm{Z}$ is the result researchers obtain. However, $\mathrm{Z}$ is continuous value, then to transform $\mathrm{Z}$ into binary data and introduce the Sigmoid function since the logistic regression can only process binary data.

$$
g(Z)=\frac{1}{1+e^{-Z}}
$$

Eventually, the prediction of function is

$$
h_{\Theta}(X)=g\left(\Theta^{T} X\right)=\frac{1}{1+e^{-\Theta^{T} X}}
$$


This function can be denoted as equation bellow, in the condition of the test data $\mathrm{X}$ and the parameters researchers obtain. Hence probability of positive $\mathrm{y}=1$ of these test data.

$$
h_{\Theta}(X)=P(y=1 \mid X ; \Theta)
$$

Correspondingly, equation bellow is negative $\mathrm{y}=0$ for these test data

$$
1-h_{\Theta}(X)=P(y=0 \mid X ; \Theta)
$$

For logistic regression in machine learning, researchers regard this regression as an optimization process.

The cost function used in logistic regression is

$$
\operatorname{COST}\left(h_{\Theta}(X), y\right)= \begin{cases}-\log \left(h_{\Theta}(X)\right) & \text { When } y=1 \\ -\log \left(1-h_{\Theta}(X)\right) & \text { When } y=0\end{cases}
$$$$
J_{\theta}=\frac{1}{m} \operatorname{COST}\left(h_{\Theta}\left(X^{i}\right), y^{i}\right)
$$

So the question becomes how to obtain the minimum value of J $\Theta$. Researchers use Gradient Descent Algorithm to obtain the value.

Researchers make a setting that the ratio of group 1,2 , 3 as $0.9,0.5,0.1$ for regression. To avoid over fitting, researchers process the data by noise treatment with amplitude of 0.02 and that complies with Standard Gaussian Distribution.

After 53 times of iteration, researchers gain the parameters of logical regression.

Parameter:

$Z=(0.5574,0.5839,0.7669,0.1154,0.8238,0.7012,0.280$ 0) $\mathrm{T}$

Gradient:

$\mathrm{G}=(0.5839,0.7669,0.1154,0.8238,0.7012,0.2800) \mathrm{T}$

\section{NEURAL NETWORK}

The neural network algorithm consists of multiple neurons connecting with each other, and the algorithm can simulate the reaction between biological neural system and objectives. By learning the information sample, to train artificial neural network and allow it to have ability of memorizing, recognizing and processing information as human brain. However, it requires no priori formula and induces rules automatically from existing data, then would obtain inherent law, indicating that it has ability of selflearning, self-adaptive, associative memory, parallel processing and non-linear change. Therefore, this algorithm is quite suitable for such problems as uncertain reasoning, judgment, recognition and classification. For any randomly chosen and normal data, researchers can use artificial neutral network algorithm to analyze it and make fitting and predictions.

Researchers select the most successful and widely use of artificial neutral network, based on Multiple-layer feedforward network on Error Back Propagation Algorithm, i.e. BP neutral network.

The learning process of BP neutral network is composed of two processes-- forward-propagating by signals and reverse-propagating by deviations. When applying forward-propagating, the pattern acts on input layer, then approach to reverse-propagating stage after hidden layer's processing, in the form of a certain seed of the output deviation. It passes through hidden layer and goes back to input layer progressively, and the deviation is shared in every layer's every unit, so researchers can obtain every layer's reference deviation as the basis to amend every unit's weight. The process of weights' amending is network learning. This process will not stop till the network output deviation reduces to acceptable level or reaches set learning times. BP network model consists input and output model, role model function, deviation evaluation model and self-learning model.

BP network is formed by connection of nodes of Inputlayer, output-layer and one or several hidden layer. This structure allows multi-layers feedforward network builds linear or nonlinear relation between input-layer and outputlayer without limiting network output in between -1 to 1 . As shown in Fig. 2.

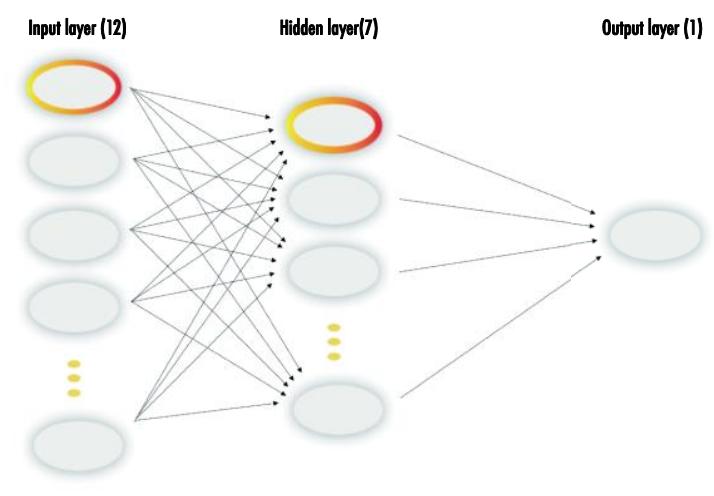

Figure 2. Our Neural Network

BP algorithm obtains the linear or nonlinear relation between input and output by "training". The process of "training" includes two stages--- forward-propagating and reverse-propagating.

Researchers establish the neural network model according to the data of 96 countries. The weights of all the neurons of its input layer are showed in table 3.

TABLE III. INPUT WEIGHT

\begin{tabular}{ccccccc}
\hline Indicator & neu $_{1}$ & neu $_{2}$ & neu $_{3}$ & neu & neu & neu \\
\hline$I_{1}$ & 1.58 & -0.73 & 0.35 & -1.29 & 2.56 & 0.19 \\
$I_{2}$ & -0.05 & -0.6 & -1.5 & 0.87 & 2.89 & 0.44 \\
$I_{3}$ & 0.15 & 0.65 & 0.35 & -1.37 & -3.16 & 0.75 \\
$I_{4}$ & 2.97 & 1.21 & -1.54 & -2.59 & -2.63 & -2.51 \\
$I_{5}$ & 1.46 & -1.67 & 1.13 & -3.6 & -1.84 & 0.79 \\
$I_{6}$ & 1.31 & -0.94 & 2.21 & 1.11 & -4.75 & 3.28 \\
$I_{7}$ & -1.24 & 1.4 & -2.85 & 3.53 & -2.55 & -0.27 \\
$I_{8}$ & -0.51 & 1.38 & 0.49 & -2.59 & 0.57 & 0.05 \\
$I_{9}$ & -0.86 & 0.28 & -2.33 & 1.48 & -0.78 & 0.27 \\
$I_{10}$ & -0.29 & -0.9 & -1.29 & -1.06 & 1.05 & 2.58 \\
$I_{11}$ & 0.84 & 2.52 & 2.61 & -0.51 & -4.87 & 1.52 \\
$C$ & -4.1 & -2.99 & 2.33 & 0.29 & 2.41 & 3.16 \\
\hline
\end{tabular}

The weight of the input layer is vector $\mathrm{w}$ $\mathrm{w}=(1.68,2.98,-1.08,1.03,-1.24,-0.37,0.91) \mathrm{T}$

\section{CONCLUSIONS}

Researchers implement the sensitivity analysis of the models. Note that there are two kinds of parameter models 
(such as K-means and neutral network) and no-parameter models (such as logistic regression).

As researchers all know, K-means is a model with initial cluster centers. Researchers repeat the experiment by generating initial point randomly and get stable results, according to which researchers divide countries into three categories and improve the stability of the model. For neutral network model, the most important undetermined parameters are the number of hidden layers and the number of neurons in each layer. Generally speaking, except deep learning model, the number of hidden layers is less than 1 . Considering the data volume at present, researchers select 6 neurons and discuss the impact that the number of neighboring neurons has on results. The impact is showed in the table 4

TABLE IV.

SENSITIVITY OF HIDDEN LAYER

\begin{tabular}{cc}
\hline The number of neurons & error \\
\hline 3 & 0.67 \\
4 & 0.55 \\
5 & 2.03 \\
6 & 0.66 \\
7 & 0.83 \\
8 & 0.71 \\
\hline
\end{tabular}

Researchers can see that the impact of the change of model parameter has on model results are acceptable.

For logistic regression model researchers experiment repeatedly and there are few differences among results.

So researchers believe that the models used in this paper are comparatively insensitive and could be promoted and widely used in practical.

Researchers use Means Clustering Algorithm of kmeans, BP neural network and Logistic Regression to build a universal model analyzing the degree of sustainable development of countries. After processing 6 selected indicators, this model will assign this country to one of the three clusters; in which group 1 represent highly sustainable development, group 2 stands for sustainable development and group 3 is unsustainable development. And the Algorithms have some advantages:

- K-Means Clustering Algorithm of k-means is simple and quick-start. Also, it can process large data with high efficiency and has a good effect of classification.

- $\quad$ BP neural network has a strong ability of nonlinear mapping, self-learning and self-adapting and basic fault-tolerant ability.

\section{ACKNOWLEDGMENT}

This work was sponsored by science Foundation of Sichuan Department of education of Sichuan Province of
China under Grant No. 13ZB0287 and the Research project of Sichuan Agricultural University under Grant No. 2014296.

\section{REFERENCES}

[1] Burton, Ian. "Report on Reports: the Common Future: The World Commission on Environment and Development." Environment: Science and Policy for Sustainable Development 29.5 (1987): 2529.

[2] Singh, Rajesh Kumar, et al. "An overview of sustainability assessment methodologies." Ecological Indicators 15.1 (2012): 281-299.

[3] Warhurst, Alyson. "Sustainability indicators and sustainability performance management." Mining, Minerals and Sustainable Development [MMSD] project report 43 (2002).

[4] Costanza, Robert, et al. "The value of the world's ecosystem services and natural capital." (1998)

[5] Serageldin, Ismail, and Christiaan Grootaert. "10. Defining social capital: an integrating view." Evaluation and Development: the institutional dimension 1 (1998): 203.

[6] United Nations. Dept. for Policy Coordination, and Sustainable Development. Indicators of sustainable development: Framework and methodologies. United Nations, 1996.

[7] Hard, P., S. Barg, and T. Hodge. "Measuring sustainable development: Review of current practices." Occasional Paper Number 17.11 (1997): 1-2.

[8] WWF, UNEP, and Global Footprint Network. "Living planet report 2004." World Wildlife Found Editor (2004)

[9] P Hardi, TJ Zdan. "Assessing sustainable development: principles in practice". Winnipeg: International Institute for Sustainable Development, 1997.

[10] Loh, J. "Living Planet Report 2002. World-Wide Fund for Nature International (WWF), UNEP World Conservation Monitoring Centre, Redefining Progress." Center for Sustainability Studies, Gland, Switzerland (2002).

[11] Loh, Jonathan. Living planet report 2000. WWF--World Wide Fund for Nature, 2000.

[12] Hails, Chris, Jonathan Loh, and Steven Goldfinger. "Living planet report 2006." WWF International, Institute of Zoology, Global Footprint Network (2006)

[13] Leape, Jim P. "Living Planet Report 2010." (2008).

[14] NI, T. Living planet report 2012. London: A Banson Production, 2012.

[15] Mieg, Harald A., Ralph Hansmann, and Peter M. Frischknecht. "National sustainability outreach assessment based on human and social capital: The case of Environmental Sciences in Switzerland." Sustainability 4.1 (2011): 17-41.

[16] Fernando, Ravi. "Sustainable globalization and implications for strategic corporate and national sustainability." Corporate Governance: The international journal of business in society 12.4 (2012): 579-589.

[17] Serageldin, Ismail. "How do researchers move forward to maintain sustainability for the future of humankind?." Technovation 33 (2013). 

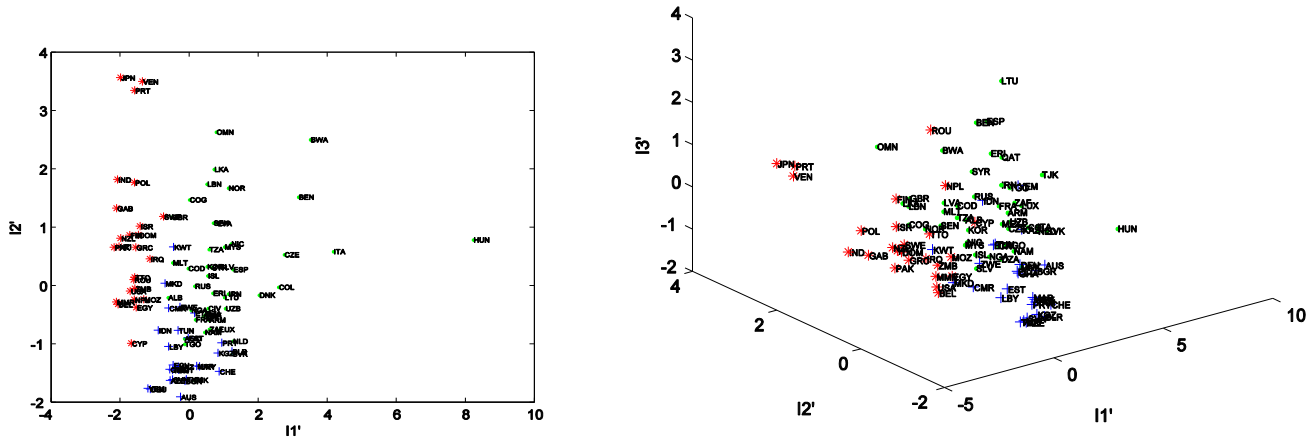

Figure 3. 2D and 3D country's group figure. 